\author{
Asian Journal of \\ Medical and Biological Research \\ ISSN 2411-4472 (Print) 2412-5571 (Online) \\ www.ebupress.com/journal/ajmbr
}

\title{
Article
}

\section{Identification and antibiogram study of bacteria isolated from different street food}

Mohamed Ahmed Khalif ${ }^{1}$, Md. Khaled Hossain ${ }^{2}$, Nazmi Ara Rumi ${ }^{2} *$, Md. Shajedur Rahman ${ }^{3}$ and Md. Aoulad Hosen $^{2}$

${ }^{1}$ Hargeisa Group Hospital, Microbiology Department, Hargeisa Somaliland

${ }^{2}$ Department of Microbiology, Hajee Mohammad Danesh Science \&Technology University, Dinajpur, Bangladesh

${ }^{3}$ Department of Medicine, Surgery and Obstetrics, Hajee Mohammad Danesh Science \&Technology University, Dinajpur, Bangladesh

*Corresponding author: Nazmi Ara Rumi, Department of Microbiology, Hajee Mohammad Danesh Science \& Technology University, Dinajpur, Bangladesh. Phone: +8801774410088; E-mail: rumi_dvm@yahoo.com

Received: 07 September 2018/Accepted: 25 September 2018/ Published: 30 September 2018

\begin{abstract}
Food borne diseases are an increasingly recognized problem involving a wide spectrum of illnesses caused by bacterial contamination of food.Microorganism poses potential human health problems and is mainly transmitted through consumption of contaminated foods .Bangladesh is one of the densely populated country where majority of the people consume cheap foods prepared in unlicensed food selling points. The objective of the present study was to investigate the microbiological quality of different street food (Amra, Fusca, Chanachur and Guava) sold by various street vendor at Dinajpur, Bangladesh. A total of 20 samples were collected randomly from street vendors and tested for the presence of bacteria following standard microbiological method used for isolation, enumaration and identification of bacreria. Among the samples all had bacterial contamination. The total viable count (TVC) in diferrent street food samples was ranged from $8.0 \times 10^{5} \mathrm{CFU} / \mathrm{g}$ to $6.7 \times 10^{7} \mathrm{CFU} / \mathrm{g}$. Among samples Escherichia coli 7(35\%), Staphylococcus spp. 6(30\%), Klebsiella spp. 5(25\%), Salmonella spp. 1(5\%) and Shigella spp. $1(5 \%)$ were isolated. Escherichia coli were found highest $3(50 \%)$ Amra samples and 2(40\%) Guava samples, then another organisms Staphylococcus spp. was found highest 2(50\%) Chanachur and 2(40\%) Fusca samples and then Klebsiella spp. was found highest 2(40\%) Fusca samples. Antibiotic sensitivity test showed that Shigella spp., Staphylococcus spp., Klebsiella spp., Salmonella spp. and Escherichia coli were sensitive to Ciprofloxacin and Salmonella spp. were resistance to Gentamycin. All isolates found resistant to Cefixime, Cefalexin, Erythromycin, Fusidic acid, Cefuroxime and Aztreonam. All of the sample harbor multidrug resistant food borne bacteria which might cause public health hazards if these antibiotic resistance transfer to human.
\end{abstract}

Keywords: street food; antibiotic; resistant; sensitivity; contamination

\section{Introduction}

Street vended foods mean ready to eat foods and beverages that are prepared and sold especially in streets or similar public places by the street vendors or merchants for consumption at the location or later without any further preparation. The street vended foods are usually under unhygienic conditions and displayed openly to a high degree of contamination. In most cases running water is not available at vending sites, washing of hands and crockery are done in bowls or buckets and sometimes without soap. Thus, from the health point of view, selling foods in the street is very controversial (Bereda et al., 2016). These street foods could be main vehicles for the transmission of severe food borne infections and fatal disease that could be life-threatening (Rane, 2011). In developing countries food sold by street vendors is the major source of food-borne illness. Although food items from these outlets are appreciated mostly for their unique flavor and for their convenience, their 
microbiological safety is not always certain (Islam et al., 2015). Food borne bacterial pathogens commonly detected in street vended foods are Bacillus cereus causes vomiting and diarrhea, Clostridium perfringens causes abdominal cramps and diarrhea, Staphylococcus spp. causes vomiting, diarrhea, loss of appetite, severe abdominal cramps and mild fever and Salmonella species causes typhoid, food poisoning and irritation and inflammation in the gastrointestinal tract (Hasan et al., 2018; Sharma et al., 2015). Knowing the microbiological quality of street vended foods is important factor to appreciate the safety problems related to street foods so that concerned bodies may take appropriate steps to improve safety and sanitation with respect to this economic sector (Muleta and Ashenafi, 2001). Vendors are often poorly educated, unlicensed, untrained in food hygiene, and they work under crude unsanitary conditions with little or no knowledge about the causes of food borne disease (Barro et al., 2007). The street foods provide a source of affordable nutrients to the majority of the people specially the low earning group in the developing countries (Muzaffar et al., 2009). Ready-to-Eat (RTE) foods could be raw overcooked, hot or chilled and can be consumed without further heat treatment (Tsang, 2002). Increased consumption of RTE foods result in food-borne illness (Sivapalasingam et al., 2004). Street foods are frequently associated with diarrhoeal diseases due to their improper handling and serving practices (Barro et al., 2006). Microbial contamination of RTE sold by street vendors and hawkers has become a major health problem for the consumers (Tambekar et al., 2008). In developing countries, drinks, meals and snacks sold by street food vendors are widely consumed by millions of people and a considerable percent of consumers have been suffering from disease like dysentery, diarrhea, enteric fever etc. (Ali et al., 2011; Das et al., 2011; Rath and Patra, 2012). In addition, multi-drug resistance of food borne microorganisms made the food safety situation more vulnerable in public health (Khairuzzaman et al., 2014). Approximately, 30 million people in Bangladesh are suffering from food borne illnesses each year (FAO, 2012). Food borne illnesses caused by microorganisms are a major national and international health problem and an important cause of death in developing countries (Garode and Waghode, 2012). Street foods in some African countries have been tested for various microorganisms of public health concern, including faecal coliforms, Escherichia coli, Staphylococcus spp., Salmonella species and Bacillus cereus. Escherichia coli and Staphylococcus spp. were recovered in a significant proportion of the food, water, hands and surface swabs tested in Harare (FAO and WHO, 2005). Foods from street-vendors are usually ready-to-eat (RTE) foods, prepared and sold on streets and other public places (Dawson and Canet, 1991). The types of street-vended food vary significantly on countries and cultures (Moy et al., 1997). According to a study from the Food and Agriculture Organization (FAO), 2.5 billion people eat street food every day. It is also recognized that street food vendors are often poor, uneducated, and lack knowledge in safe food handling, environment, sanitation and hygiene, mode of food display, food service and hand washing, sources of raw materials, and use of potable water (Hassan et al., 2018). Consequently, street foods are perceived to be a major public health risk (Bhowmik, 2010). As food is biological in nature, it is capable of supporting the growth of microorganisms and food borne diseases result from the ingestion of contaminated foods and food products (Sheth et al., 2005). In Bangladesh, street foods are mostly prepared and processed manually and sold to the public at various lot terminals, by the roadside or by itinerant vendors (Mamun et al., 2013). The vendors in Bangladesh lack of education regarding the basic food safety issues. Vendors generally use carts and stands, where they do not have easy access to running water, furthermore dish and hand washing is done using the same bucket, sometimes even without soap. Garbage and waste water are typically discarded in the streets nearby and thus attracting and providing food for rodents and insects (Bryan $e t$ al., 1988). Foodborne bacterial agents are the leading cause of severe and fatal foodborne illnesses. Of the many thousands' different bacterial species more than $90 \%$ of food-poisoning illnesses are caused by species of Staphylococcus, Salmonella, Clostridium, Campylobacter, Listeria, Vibrio, Bacillus, and entero pathogenic Escherichia coli (Schmidt et al., 2003). In addition, resistance of foodborne microorganisms in multi-drug made the food safety situation more vulnerable in public health (Ali et al., 2011). Street food feeds millions of people daily with a wide variety of foods that are relatively cheap and easily accessible (Latham, 1997; Tambekar et al., 2011). Street food is intimately connected with take-out, junk food, snacks, and fast food (Lues et al., 2006). Street food is food obtained from a street side vendor, often from a makeshift or portable stall (FAO, 2007). The objective of this research work was to isolate and identify the bacteria that present in different street vended foods and study of their antimicrobial susceptibility patterns.

\section{Materials and Methods}

The entire study is divided into three steps. The first step includes the total viable counts of the collected samples. The second steps includes isolation and identification of the bacteria from the sample by cultural, morphological and biochemical test. Third step includes evaluation of antibiotics sensitivity against the isolated bacteria. 


\subsection{Collection of samples}

The present research work was conducted during the period from July to December 2017, in the Bacteriology Laboratory of the Department of Microbiology, Faculty of Veterinary and Animal Science, Hajee Mohammad Danesh science \& Technology University (HSTU), Dinajpur. A total number of twenty Food samples samples were included in this study. Sample was collected from different street vended foods in Lilly More, Basharhat, Doshmile and College More of sadarupazilla at Dinajpur district. Food samples included Amra, Fusca, Chanachur, and Guava (pearah). Approximately 300g of each food sample was collected using the vendors serving utensils, take parcel and placed into sterile plastic bags. All the collected samples were kept on an icebox during transportation to the laboratory and stored at $4^{\circ} \mathrm{C}$ until testing. They were analyzed within 24 hours of sampling.

\subsection{Preparation of sample}

Adequate amount of different street food (Amra, Fusca, chanachur, and Guava) samples were uniformly homogenized in mortar and pastel using a sterile diluent as per recommendation of (Balamurugan et al., 2013). A homogenized suspension was made with the help of mortar and pastel. A quantity of 10 gm homogenate sample of each different street was taken aseptically with a sterile spoon and transferred carefully into a sterile pastle containing $90 \mathrm{ml}$ of PBS. Thus 1:10 dilution of the samples was obtained.

\subsection{Enumeration of total viable count (TVC)}

$50 \mu 1$ of each fivefold dilution was transferred and spread onto Plate Count Agar using a micropipette for each dilution for the determination of total bacterial count. The diluted samples were spread as quickly as possible on the surface of the plate. The plates were kept in an incubator at $37^{\circ} \mathrm{C}$ for $24 \mathrm{hrs}$. After incubation, plates exhibiting 30-300 colonies were counted. The average number of colonies in particular dilution was multiplied by the dilution factor to obtain the total viable count. The total viable count was calculated according to ISO (1995). The results of the total bacterial count were expressed as the number of colony forming units (CFU) per $\mathrm{ml}$ of food samples.

\subsection{Isolation of associated bacteria}

Bacteriological examination was carried out using standard method for aerobic bacteria (Brown, 2005). Each sample of Amra, Fusca, chanachur, and Guava samples were inoculated separately in nutrient broth (NB) to promote growth of bacteria. Each group of these media were incubated at $37^{\circ} \mathrm{C}$ for overnight. The colonies on primary cultures were repeatedly subcultured by streak plate method (Cheesbrough, 1985) until the pure culture with homogenous colonies were obtained. Media such as Nutient agar, MacConkey agar, Eosin Methylene Blue agar, Salmonella Shigella (SS) agar, and Manitol Salt Agar (MSA) were used for sub-cultures and incubated at $37^{\circ} \mathrm{C}$ for 24 hours for growth.

\subsection{Identification of associated bacteria}

The cultural examination of street food (Amra, Fusca, Chanachur, and Guava) samples for bacteriological study was done according to the standard method International Commission on Microbiological Specifications for Foods (ICMSF, 1985). Identification of bacteria was performed on the basis of colony morphology Gram's staining reaction and biochemical test.Biochemical tests, such as sugar fermentation, coagulase, catalase, MR, VP, and indole tests, were performed as per the standard methods (Cheesbrough, 1985).

\subsection{Antibiogram study}

To determine the drug sensitivity and resistance patterns of isolated organisms used different types of commercially available antibiotic discs, (Mast diagnostics Mersey side, UK.). The antibiotic resistance was determined by Kirby-Bauer disc diffusion technique using Mueller-Hinton agar (Difco), according to the guidelines of clinical and Laboratory Standards Institute (CLSI, 2007). After overnight incubation at $37{ }^{\circ} \mathrm{C}$, the diameter in millimeters of the zones of inhibition around each of the antimicrobial discs was recorded and categorized as resistant, intermediate and sensitive in accordance with company recommendations (Cappuccino and Carpenter, 2005).

\section{Results and Discussion}

\subsection{Results of microbial load by total viable count (TVC)}

The (TVC) of different street food (Amra, Fusca, Chanachur and Guava) samples collected from different vendors are shown in Table 1. The highest numbers of bacterial colonies were observed inAmra sample 
$\left(6.7 \times 10^{7} \mathrm{CFU} / \mathrm{g}\right)$ followed by Fusca sample $\left(6.3 \times 10^{7} \mathrm{CFU} / \mathrm{g}\right)$, Chanachur sample $\left(6.0 \times 10^{7} \mathrm{CFU} / \mathrm{g}\right)$ and Guava sample $\left(5.8 \times 10^{7} \mathrm{CFU} / \mathrm{g}\right)$.

Table 1. Microbial load by total viable count (TVC).

\begin{tabular}{llll}
\hline Place of vendor (Type of food) & Dilution & Number of colony & Total viable count (TVC) \\
\hline & $10^{-1}$ & Over 300 & TNTC \\
Basherhat & $10^{-2}$ & Over 300 & TNTC \\
(Chanachur) & $10^{-3}$ & 83 & $8.3 \times 10^{5} \mathrm{CFU} / \mathrm{g}$ \\
& $10^{-4}$ & 75 & $7.5 \times 10^{6} \mathrm{CFU} / \mathrm{g}$ \\
& $10^{-5}$ & 60 & $6.0 \times 10^{7} \mathrm{CFU} / \mathrm{g}$ \\
Doshmile & $10^{-1}$ & Over 300 & TNTC \\
(Guava) & $10^{-2}$ & Over 300 & $\mathrm{TNTC}$ \\
& $10^{-3}$ & 80 & $8.0 \times 10^{5} \mathrm{CFU} / \mathrm{g}$ \\
& $10^{-4}$ & 66 & $6.6 \times 10^{6} \mathrm{CFU/g}$ \\
College more & $10^{-5}$ & 58 & $5.8 \times 10^{7} \mathrm{CFU} / \mathrm{g}$ \\
(Fusca) & $10^{-1}$ & Over 300 & TNTC \\
& $10^{-2}$ & Over 300 & TNTC \\
& $10^{-3}$ & 97 & $9.7 \times 10^{5} \mathrm{CFU} / \mathrm{g}$ \\
Lilymore & $10^{-4}$ & 70 & $7.0 \times 10^{6} \mathrm{CFU} / \mathrm{g}$ \\
(Amra) & $10^{-5}$ & 63 & $6.3 \times 10^{7} \mathrm{CFU} / \mathrm{g}$ \\
& $10^{-1}$ & Over 300 & $\mathrm{TNTC}$ \\
& $10^{-2}$ & Over 300 & TNTC \\
& $10^{-3}$ & 92 & $9.2 \times 10^{5} \mathrm{CFU} / \mathrm{g}$ \\
\hline
\end{tabular}

\subsection{Results of bacteriological investigation}

A total of 20 different street food (Amra, Fusca, Chanachur and Guava) samples were collected from different places in Dinajpur for this study. Among 20 different street food (Amra, Fusca, Chanachur, and Guava) samples, Shigella spp., Staphylococcus spp., Klebsiella spp., Salmonella spp. and Escherichia coli were found.

\subsection{Results of isolation of bacteria from street vended food}

Five genera of bacteria such as Shigella spp., Staphylococcus spp., Klebsiella spp., Salmonella and Escherichia coli were isolated from different street food (Amra, Fusca, Chanachur and Guava) samples. During the study period a total 20 samples were collected from different street food. In case of Amra 3(50\%) positive for Escherichia coli, 1(16.66\%) positive for Staphylococcus spp., 1(16.66\%) positive for Klebsiella spp. and 1(16.66\%) were positive for Shigella spp. In case of Chanachur 2(50\%) positive for Staphylococcus spp., 1(25\%) positive for Escherichia coli and 1(25\%) were positive for Klebsiella spp. In case of Fusca 2(40\%) positive for Staphylococcus spp. and Klebsiella spp. and 1(20\%) were positive for Escherichia coli. In case of Guava 2(40\%) positive for Escherichia coli, 1(20\%) positive for Staphylococcus spp. and 1(20\%) were positive for Klebsiella spp. respectively. In 20 street food samples Escherichia coli were found highest 3(50\%) Amra samples and 2(40\%) Guava samples, then another organisms Staphylococcus spp. was found highest 2(50\%) Chanachur and 2(40\%) Fusca samples and then Klebsiella spp. was found highest 2 (40\%) Fusca samples which were shown in Table 2.

Table 2. Results of isolation of bacteria from street vended food.

\begin{tabular}{lllllcr}
\hline \multirow{2}{*}{ Bacterial isolate } & \multicolumn{3}{c}{ Types of sample } & \multirow{2}{*}{ Percentage $(\%)$} \\
\cline { 2 - 5 } & Amra & Chanachur & Fusca & Guava & Total & $35 \%$ \\
E. coli & $3(50 \%)$ & $1(25 \%)$ & $1(20 \%)$ & $2(40 \%)$ & 7 & $30 \%$ \\
Staphylococcus spp. & $1(16.66 \%)$ & $2(50 \%)$ & $2(40 \%)$ & $1(20 \%)$ & 6 & $25 \%$ \\
Klebsiella spp. & $1(16.66 \%)$ & $1(25 \%)$ & $2(40 \%)$ & $1(20 \%)$ & 5 & $5 \%$ \\
Shigella spp. & $1(16.66 \%)$ & $0(0 \%)$ & $0(0 \%)$ & $0(0 \%)$ & 1 & $5 \%$ \\
Salmonella spp. & $0(0 \%)$ & $0(0 \%)$ & $0(0 \%)$ & $1(20 \%)$ & 1 & 20 \\
Total bacteria identified & 6 & 4 & 5 & 5 & & $100 \%$ \\
\hline
\end{tabular}

\subsection{Results of isolation of bacteria by cultural test}

Cultural characteristics of each type of bacteria isolated from different street food were studied for the determination of size, shape and colony characteristics in various bacteriological media. The staining property 
of primary culture of each of the different street food samples indicated the presence of more than one type of bacteria in the same smear. The pure cultures of the organism from each mixed culture were obtained by repeated streak plate method using different simple and selective solid media for study. The individual cultural characteristics of bacterial isolates are presented in Table 5. The cultural characteristics of Klebsiella spp., Staphylococcus spp., Shigella spp., Salmonella spp. and E. coli exhibited on the media are presented in Table 3.

Table 3. Cultural characteristics of the bacterial isolates of different street food.

\begin{tabular}{llll}
\hline Sl. No & Suspected case of bacteria & Name of media & Cultural characteristics \\
\hline 01 & Klebsiella spp. & MacConkey agar & Large, mucoid, bright pink \\
02 & Staphylococcus spp. & MS agar & Medium yellowish colony \\
03 & Shigella spp. & SS Agar & Small non-lactose fermented colony \\
04 & Salmonella spp. & SS Agar & Small non-lactose fermented \\
05 & Escherichia. Coli & EMB agar, & with black center colony \\
\hline
\end{tabular}

Notes: MS Mannitol salt, EMB = Eosin methylene blue, SS=Salmonella Shigella

\subsection{Results of staining characteristics of the isolated bacteria}

The staining characteristics of the isolated organisms were determined according to Gram's staining technique. Morphological and staining characteristics of bacteria recorded from Amra, Fusca, Chanachur and Guava samples by Gram's staining are presented in Table 4.

Table 4. Morphological and staining properties of the bacterial isolates from Amra, Fusca, Chanachur and Guava by Gram's staining.

\begin{tabular}{llll}
\hline \multicolumn{1}{c}{ Staining characteristics } & & \multirow{2}{*}{ Remarks } \\
\hline Shape & Arrangement & Gram's staining character & Klebsiella spp. \\
\hline Rod in shape & Single, pairs or cluster & $(-)$ ve & Staphylococcus spp. \\
Cocci in shape & Arranged in grapes like cluster & $(-)$ ve & Shigella spp. \\
Rod in shape & Single or pair & $(-)$ ve & Salmonella spp. \\
Rod in shape & Single or pair & $(-)$ ve & E. coli \\
Short plump rods & Single, paired or in short chain & & \\
\hline
\end{tabular}

Notes: $(+) \mathrm{Ve}=$ Positive; $(-) \mathrm{Ve}=$ Negative

\subsection{Results of biochemical tests of different isolates}

Isolated E. coli, Salmonella spp., Staphylococcus spp. were positive and Klebsiella spp. was negative for methyl red test. All isolates were positive for catalase test with gas bubble formation. All isolates were negative for oxidase test with no colour change except Staphylococcus spp. E. coli, Staphylococcus spp. were negative and Salmonella spp. and Klebsiella spp. were positive for voges-proskauer test.

\subsection{Results of antibiotic sensitivity tests}

A total of five isolates such as Klebsiella spp., Staphylococcus spp., Shigella spp., Salmonella spp. and E. coli were subjected to antibiotic sensitivity assay. The results of antibiotic sensitivity assay are presented in Tables 6 , 7, 8, 9 and 10. Antibiotic sensitivity test showed that Shigella spp., Staphylococcus spp., Klebsiella spp., Salmonella spp. and Escherichia coli were sensitive to Ciprofloxacin. Staphylococcus spp., Klebsiella spp., Escherichia coli were sensitive to Gentamycin and Salmonella spp. were resistance to Gentamycin. Klebsiella spp. and Staphylococcus spp. were sensitive to Neomycin and Shigella spp. were resistance to Neomycin. Klebsiella spp. and Shigella spp. were intermediate sensitive to Kenamycin. All isolates found resistant to Cefixime, Cefalexin, Erythromycin, Fusidic acid, Cefuroxime and Aztreonam. 
Table 5. A total of 5 bacterial species were identified from 20 isolates.

\begin{tabular}{|c|c|c|c|c|c|c|c|c|c|c|}
\hline SL No. & $\mathbf{C a}$ & $\mathbf{O x}$ & Ind & Cit & MR & VP & MIU & Spore & TSI & Identification \\
\hline 1 & + & - & - & + & - & + & - & - & $\begin{array}{l}\text { Yellow butt, } \\
\text { Yellow slant, } \\
\text { Gas }=(+\mathrm{ve}) \\
\mathrm{H}_{2} \mathrm{~S}=(-\mathrm{ve})\end{array}$ & Klebsiella spp. \\
\hline 2 & + & + & - & - & + & + & - & - & $\begin{array}{l}\text { Slant and Butt } \\
\text { both acidicH }{ }_{2} \mathrm{~S}=(-\mathrm{ve}) \\
\text { Gas }=(-\mathrm{ve})\end{array}$ & Staphylococcus spp. \\
\hline 3 & + & - & - & + & + & - & + & - & $\begin{array}{l}\text { Slant alkaline } \\
\text { Butt acidic } \\
\mathrm{H}_{2} \mathrm{~S}=(+\mathrm{v}) \\
\mathrm{GaS}=(-\mathrm{ve})\end{array}$ & Salmonella spp. \\
\hline 4 & + & - & - & + & + & - & - & - & $\begin{array}{l}\text { Slant alkaline } \\
\text { Butt acidic } \mathrm{H}_{2} \mathrm{~S}=(-\mathrm{v}) \\
\text { Gas }=(-\mathrm{ve})\end{array}$ & Shigella spp. \\
\hline 5 & + & - & + & - & + & - & + & - & $\begin{array}{l}\text { Yellow butt, } \\
\text { Yello slant, } \\
\text { Gas }=(+v e) \\
\mathrm{H}_{2} \mathrm{~S}=(-\mathrm{ve})\end{array}$ & Escherichia coli \\
\hline
\end{tabular}

Legends: SL No. = Serial Number, Cat: Catalase test, Ox: Oxidase test, md: Indole test, Cit: Citrate Utilization test, MR: Methyl red; VP: Voges-Proskauer, TSI: Triple Sugar Iron, MIU: Motility, Indole and Urease test, $(+)=$ Positive; $(-)=$ Negative, $\mathrm{H} 2 \mathrm{~S}=$ hydrogen sulphide.

Table 6. Antimicrobial profile of Klebsiells spp.

\begin{tabular}{llll}
\hline Organism & Name of the antibiotics & Zone of inhibition (mm) & Interpretation \\
\hline & Ciprofloxacin (CIP) & 30 & $\mathrm{~S}$ \\
Klebsiells spp. & Gentamycin (GEN) & 23 & $\mathrm{~S}$ \\
& Erytromycin (E) & 0 & $\mathrm{R}$ \\
& Kanamycin (K) & 25 & $\mathrm{~S}$ \\
& Neomycin (N) & 22 & $\mathrm{~S}$ \\
\hline
\end{tabular}

Note: $R=$ Resistant, $S=$ Sensitive, $I=$ Intermediate

Table 7. Antimicrobial profile of Staphylococcus spp.

\begin{tabular}{llll}
\hline Organism & Name of the antibiotics & Zone of inhibition (mm) & Interpretation \\
\hline & Ciprofloxacin (CIP) & 30 & $\mathrm{~S}$ \\
Staphylococcus spp. & Gentamycin (GEN) & 25 & $\mathrm{~S}$ \\
& Erytromycin (E) & 10 & $\mathrm{R}$ \\
& Fusidic Acid (FD) & 0 & $\mathrm{R}$ \\
& Neomycin (N) & 20 & $\mathrm{~S}$ \\
\hline
\end{tabular}

Note: $\mathrm{R}=$ Resistant, $\mathrm{S}=$ Sensitive, $\mathrm{I}=$ Intermediate

Table 8. Antimicrobial profile of Shigella spp.

\begin{tabular}{llll}
\hline Organism & Name of the antibiotics & Zone of inhibition (mm) & Interpretation \\
\hline & Ciprofloxacin (CIP) & 35 & $\mathrm{~S}$ \\
Shigella spp. & Gentamycin (GEN) & 20 & $\mathrm{~S}$ \\
& Erytromycin (E) & 09 & $\mathrm{R}$ \\
& Kanamycin (K) & 17 & $\mathrm{I}$ \\
& Neomycin (N) & 20 & $\mathrm{R}$ \\
\hline
\end{tabular}

Note: $R=$ Resistant, $\mathrm{S}=$ Sensitive, $\mathrm{I}=$ Intermediate 
Table 9. Antimicrobial profile of Salmonella spp.

\begin{tabular}{llll}
\hline Organism & Name of the antibiotics & Zone of inhibition (mm) & Interpretation \\
\hline & Gentamycin (GEN) & 5 & $\mathrm{R}$ \\
& Ciprofloxacin (CIP) & 22 & $\mathrm{~S}$ \\
\multirow{5}{*}{ Salmonella spp. } & Cefixirne (CfM) & 16 & $\mathrm{I}$ \\
& Cefalexin (CN) & 0 & $\mathrm{R}$ \\
& Penicillin-g (P) & 0 & $\mathrm{R}$ \\
& Aztreonam (ATM) & 0 & $\mathrm{R}$ \\
& Cefuroxime (CXM) & 0 & $\mathrm{R}$ \\
\hline
\end{tabular}

Note: $\mathrm{R}=$ Resistant, $\mathrm{S}=$ Sensitive, $\mathrm{I}=$ Intermediate

Table 10. Antimicrobial profile of against E. coli.

\begin{tabular}{llll}
\hline Organism & Name of the antibiotics & Zone of inhibition (mm) & Interpretation \\
\hline \multirow{4}{*}{ E. coli } & Gentamycin (GEN) & 25 & $\mathrm{~S}$ \\
& Ciprofloxacin (CIP) & 21 & $\mathrm{~S}$ \\
& Cefixirne (CfM) & 0 & $\mathrm{R}$ \\
& Cefalexin (CN) & 0 & $\mathrm{R}$ \\
& Penicillin-G (P) & 0 & $\mathrm{R}$ \\
& Aztreonam (ATM) & 0 & $\mathrm{R}$ \\
& Cefuroxime (CXM) & 0 & $\mathrm{R}$ \\
\hline
\end{tabular}

Note: $\mathrm{R}=$ Resistant, $\mathrm{S}=$ Sensitive, $\mathrm{I}=$ intermediate

\section{Conclusions}

The present study was conducted for the isolation, identification and antibiotic sensitivity of the bacteria isolated from different street food. Presence of coliforms in the sample might be due to poor quality of water, unhygienic vendor places and poor personal hygiene of vendors. Most Street vendors were illiterate and they did not have a clear hygienic knowledge about the preparation, storage and serving of the food. All isolates found resistant to Cefixime, Cefalexin, Erythromycin, Fusaric acid, Cefuroxime and Aztreonam. The results of this study suggested that although RTE foods are cheap and economical but they are not healthy due to lack of hygienic measures, dirty utensils, and vendor's hygiene. These factors contributing many species of bacteria but major pathogen is E. coli, Salmonella spp. Shigella spp., Klebsiella spp. and Staphylococcus spp. Basic and main source of bacterial infection is poor hygienic measures and this problem may be solved by improving supervision in food handling procedure, extended consumer education on transmission of enteric food borne diseases and food safety risks. So that street vended RTE foods should be manufactured under Good Hygienic Practices and conservation practices should be developed in order to minimize the microbial contamination of food.

\section{Acknowledgements}

This research work was supported by Department of Microbiology, Hajee Mohammad Danesh Science \& Technology University, Dinajpur, Bangladesh.

\section{Conflict of interest}

None to declare.

\section{References}

Ali M, MR Khan and ML Saha, 2011. Antibiotic resistant patterns of bacterial isolates from ready-to-eat (RTE) street vended fresh vegetables and fruits in Dhaka City. Bangladesh J. Sci. Res., 24: 127-134.

Barro N, AR Bello, Y Itsiembou, A Savadogo, CAT Owattara, P Nikiema, De SC and AS Traore, 2007. Street vended foods Improvement: Contamination Mechanism and Application of food safety objective strategy: Critical Review. Pakistan J. Nutr., 6:1-10.

Barro N, AR Bello, S Aly, CAT Ouattara, AJ IIboudo and AS Traore, 2006. Hygienic status and assessment of dishwashing waters, utensils, hands, and pieces of money from street food processing sites in Ouagadougou (Burkina Faso). Afr. J. Biotechnol., 5: 1107-1112. 
Bereda T, Y Emerie, M Reta and H Asfaw, 2016. Microbiological Safety of Street Vended Foods in Jigjiga City, Eastern Ethiopia. Ethiop J. Health Sci., 26: 161.

Bhowmik, 2010. Street Vendors in the Global Urban Economy, Routledge: Taylor \& Francis, New Delhi, India.

Bryan FL, SC Michanie, P Alvarez and A Paniagua, 1988. Critical control points of street. vended foods in the Dominican Republic. J. Food Prot., 51: 373-383.

Buxton A and G Fraser, 1977. Animal Microbiology. Vol. 1. Blackwell Scientific Publications, Oxford, London, Edinburg, Melbourne. 15: 177-183.

Cappuccino $\mathrm{N}$ and D Carpenter, 2005. Invasive exotic plants suffer less herbivory than non-invasive exotic plants. Biol. Lett., 1: 435-438.

Cheesbrough M, 1985. Medical laboratory manual for tropical countries. Istedition. Microbiology. English Language Book Society, London. pp. 400-480.

Das M, CC Rath and UB Mohapatra, 2011. Bacteriology of a most popular street food (Panipuri) and inhibitory effect of essential oils on bacterial growth. J. Food Sci. Technol., 49: 564-571.

Dawson RJ and C Canet, 1991. International activities in street foods. J. Food Control, 2: 135-139.

FAO and WHO, 2005. Informal food distribution sector in Africa (street foods): Importance and challenges. Proceedings of the FAO/WHO Regional Conference on Food Safety for Africa, October 3-6, 2005, Harare, Zimbabwe.

FAO, 2007. The informal food sector" http://www.informalfood.unibo.it 2007-11-23

FAO, 2012. The State of Food Insecurity in the World. http://www. fao.org/docrep/016/i3027e/ i3027e00.htm.

Garode AM and SM Waghode, 2012. Bacteriological status of street-vended foods and public health significance: A case study of Buldana District, MS, India. ISCA J. Biol. Sci., 1: 69-71.

Hasan M, SML Kabir, T Rahman and YA Sarker, 2018. Bacteriological quality assessment of buffalo meat collected from different districts of Bangladesh with particular emphasis on the molecular detection and antimicrobial resistance of the isolated Salmonella species. Asian Australas. J. Food Saf. Secur., 2: 12-20.

Hassan MS, SML Kabir, YA Sarker and T Rahman, 2018. Bacteriological assessment of tap water collected from different markets of Mymensingh, Gazipur and Sherpur districts of Bangladesh with special focus on the molecular detection and antimicrobial resistance of the isolated Escher. Asian Australas J. Food Saf. Secur., 2: 21-8.

Islam S, N Nasrin, F Rizwan, L Nahar, A Bhowmik, SA Esha, KA Talukder, M Akter, A Roy and M Ahmed, 2015. Microbial contamination of street vended foods from a university campus in Bangladesh. Southeast Asian J. Trop. Med. Public Health, 46: 480-485.

Khairuzzaman M, FM Chowdhury, S Zaman, AA Mamun and ML Bari, 2014. Food safety challenges towards safe, healthy and nutritious street foods in Bangladesh. Int. J. Food Sci., Article ID 483519, 9 pages.

Latham MC, 1997. Human nutrition in tropical Africa. FAO, Rome. pp. 329-437.

Lues JFR, MR Rasephei, P Venter and MM Theron, 2006. Assessing food safety and associated food handling practices in street food vending. Int. J. Environ. Health Res., 16: 319-328.

Mamun MA, MM Rahman and TC Turin, 2013. Microbiological quality of selected street food items vended by school based street food vendors in Dhaka, Bangladesh. Int. J. Food Microbiol., 166: 413-418.

Merchant LA and RA Packer, 1967.Veterinary Bacteriology and Virology. Seventhedi. The Iowa University Press, Ames, Iowa USA. 286-306.

Moy G, A Hazzard and F Kiiferstein, 1997. Improving the safety of street-vended food. World Health Status, 50: 124-131.

Muleta D and M Ashenafi, 2001. Bacteriological profile and holding temperatures of street-vended foods from Addis Ababa. Int. J. Environ. Health Res., 1: 95105.

Muzaffar AT, I Huq and BA Moreik, 2009. Entrepreneurs of the streets: An analytical work on the street food vendors of Dhaka city. Int. J. Busi. Manag., 4: 80-88.

Olaitan JO, OB Shittu and AA Akinliba, 2011. Antibiotic resistance of enteric bacteria isolated from duck droppings. J. Appl. Biosci., 45: 3008-3018.

Rane S, 2011. Street Vended Food in Developing World: Hazard Analyses. Indian J. Microbiol., 51: 100-106.

Rath CC and S Patra, 2012. Bacteriological quality assessment of selected street foods and antibacterial action of essential oils against food borne pathogens. Int. J. Food Safety, 14: 5-10.

Schmidt R, MG Ren'ee, L Douglas, Archer and RS Keith, 2003. General Overview of the Causative Agents of Food bomeIllness,\| This document is FSHNO33, one of a series of the Food Science and Human Nutrition Department, Florida Cooperative Extension Service, WAS, University of Florida.

Sharma A, H Bhardwaj and I Ravi, 2015. Microbiological analysis of street vended food in West Delhi. Indian J. Appl. Res., 5: 291-294. 
Sheth M, R Gurudasani and R Mudbidri, 2005. Identification of hazards in street foods of Vadodara, India. J. Nutr. Diet., 42: 266274.

Sivapalasingam S, CR Friedman, L Cohen and RV Tauxe, 2004. Fresh produce a growingcause of outbreaks of food borne illness in the United States, 1973 through 1997. J. Food Prot., 67: 2342-2353.

Tambekar D, H Kulkarni, RVSD Shirsat and DG Bhadange, 2011. Bacteriological quality of street vended food Panipuri. A case study of Amravati city (ms) India. Biosci. discov., 2: 350-354.

Tambekar DH, VJ Jaiswal, DV Dhanorkar, PB Gulhane and MN Dudhane , 2008. Identification of microbiological hazards and safety of ready-to-eat food vended in streets of Amravati city, India. J. Appl. Biosci., 7: 195-201.

Tsang D, 2002. Microbiological guidelines for ready to eat food. Road and Environmental Hygein department, Hong Kong, 115-116. 